\title{
Primary special school teachers' knowledge and beliefs about supporting learning in numeracy
}

Full contact details

Dr Lio Moscardini

Senior Lecturer

Course Leader MEd in Inclusive Education

School of Education

Faculty of Humanities and Social Sciences

University of Strathclyde

Lord Hope Building

141 St James' Road

Glasgow G4 0LT

Tel. 01414448074

Email1.moscardini@strath.ac.uk

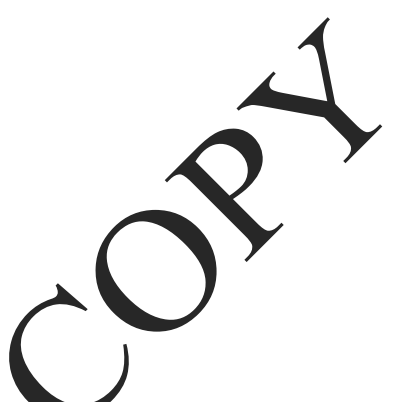

\section{Abstract}

This article presents findings from a qualitative study of a group of twetve teachers in primary special schools in Scotland for children with moderate learning difftculties. It sets out an analysis of classroom observations and interviews that explored teache s' knowledge and beliefs about teaching and learning in mathematics with children with moderateanng difficulties. The teachers were interviewed pre- and post-intervention; this was research-based professional development programme in children's mathematical thin (nng Cognitively Guided Instruction) which teachers then developed in their classrooms. The findings showed that prior to the professional development the teachers had a limited knowledge of children's mathematical development with teaching frequently informed by intuitive beliefs/and dated and sometimes discredited practices. Most teachers had low expectations of children with learning difficulties. Post-intervention the teachers reviewed this stance and afrmed that a deeper understanding of children's mathematical thinking provided a more secure for instruction. They also recognised the extent to which learners were constr ine by existing classroom practices. The paper argues for the commonality of this knowledgenase and considers the problematic nature of viewing such knowledge as sector specific.

\section{Key vords}

Moderate learning difficulties; inclusive pedagogy; teachers' knowledge and beliefs; pedagogical content knowledge 


\section{Primary special school teachers' knowledge and beliefs about supporting learning in numeracy}

\section{Introduction}

This article presents the findings of a study which explored Scottish primary special school teachers' knowledge and beliefs about the teaching and learning of mathematics with children identified as having moderate learning difficulties before and after a period of professional development which focussed on children's mathematical thinking. The study focused specifically on numeracy as an aspect of mathematics rather than other elements of the mathematics curriculum. Discussion of mathematics in this article relates solely to numeracy. Within this context numeracy is regogaised as the ability to process, communicate and interpret numerical information (Askew, Brgm Rhodes, et al., 1997, p.11).

There has been a growing body of research evidence, over the las 30 years, in the area of mathematics teaching connecting effective learning with teachers' knowedg of how children are conceptualising (and misconceptualising) mathematical principlas (Naclellan, 2012; Jacobs, Lamb \& Philipp, 2010; Greer \& Meyen 2009; Ball, Thames \& helps 2008; Ryan \& Williams, 2007; Peterson, Fennema, Carpenter \& Loef, 1989; Carpente Rennema, Peterson \& Carey, 1988).The recognition of this kind of pedagogical knowledge as relevant for all children connects with inclusive arguments which promote the extengion of whert is commonly available for all as a means of accommodating difference (Ylonen \& No vich, 2012; Florian \& Black-Hawkins, 2011; Norwich \& Nash, 2011; Hart, Drummond \& McIntre, 2007). This challenges the notion of particular pedagogical knowledge specific to particu, groups of learners (Florian \& Linklater, 2010; Lewis \& Norwich, 2005).

Teachers' pedagogical decision are driven by the complex interplay between knowledge, beliefs and contextual factors (I@iniv,2013; Turner, Christensen \& Meyer, 2009). Beliefs about the nature of teachers' knowledge, the kind of knowledge which teachers consider desirable and their capacity to support partiolar learners relate to the teaching of pupils with additional support needs (Florian, 2008) an the area of mathematics teaching (Ma, 1999). However there is little empirical evidence of how trese aspects of teacher knowledge and beliefs relate to the instruction of children with moderate learning difficulties (Ylonen \& Norwich, 2012; Fletcher-Campbell, 2005).

\section{Knowledge and beliefs}

There is an important relationship between teachers' beliefs about the content of their teaching and their actual knowledge of how this content can be structured and taught (Walshaw, 2012; Turner, Christensen \& Meyer, 2009; Peterson, Fennema, Carpenter et al., 1989). Instructional practice is not simply determined by teachers' beliefs; other factors contribute to the complexity of this outcome: 


\section{Primary special school teachers' knowledge and beliefs about supporting learning in numeracy}

curriculum guidelines, policies, pupil behaviour and management systems among other things. Teachers' beliefs, whilst not being exclusive determinants of classroom culture, have a significant bearing on it (Lloyd, 2002; Peterson, Fennema, Carpenter et al., 1989). Teachers' knowledge also has a significant influence on classroom practice (Empson \& Junk, 2004; Hiebert, Gallimore \& Stigler, 2002) but the boundaries between knowledge and beliefs are not always clear. In the blurring between knowing and believing, belief is perceived as the weaker of the two conditions (Wilson and Cooney, 2003, p131). However, if in the course of confronting new or different pedagogical approaches teachers' beliefs are challenged (Lloyd, 2002), these experiences may lead to a) growth in knowledge and a change in prior held beliefs.

Pedagogies that are inclusive and supportive of all learners require more than the denelopment of domain-specific knowledge; the current focus on teachers' subject knowlodge in mathematics (Donaldson, 2011; Middleton, 2010; DCSF, 2008) provides an incomplete pjeture of the kind of development required. Strong mathematical knowledge is pot necessarily linked to a deep understanding of children's mathematical thinking (Empson \& Junk 2004). However knowledge of children's mathematical thinking can be a powerful ifstruct onal pointer (Fennema, Franke, Carpenter et al., 1993) leading to higher achievement (Peterson, Fennema, Carpenter et al., 1989) which facilitates an educational response to the learing needs of pupils who struggle in their mathematical learning (Behrend 2003; Emps $n$ 2003). Responding to the needs of individuals on the basis of teachers' knowledge of childen thinking is both challenging and complex and is connected to the type of professional de elopment that teachers undertake (Jacobs, Lamb \& Philipp, 2010).

If better outcomes for leakners can be achieved by developing teachers' own mathematical competence, such a conern be deemed by some to be less of an issue for teachers working with those children functioning at the early stages of their mathematical learning. In other words, because children are wofking with more fundamental mathematical principles, then their teachers only require suffient mathematical knowledge to support these fundamental understandings. However research axidence would refute this proposition suggesting that all teachers require an informed know dge of children's mathematical thinking (Jacobs, Lamb \& Phillip, 2010; Empson \& Junk 2004; Fennema, Franke, Carpenter et al., 1993). Shulman's (1986) construct of pedagogical content knowledge (PCK) affords a more complex representation of the type of knowledge required by teachers. It centres on the synthesis of knowledge of subject matter, teaching approaches, the curriculum and the learners. It is a uniquely integrated form of knowledge possessed by those who teach as opposed to those who are experts in subject matter. The concept of $P C K$ has been elaborated further in the field of mathematics teaching taking into account the type of specialised 


\section{Primary special school teachers' knowledge and beliefs about supporting learning in numeracy}

knowledge involved in understanding children's mathematical thinking and how this knowledge might usefully support student learning (Ball, Thames \& Phelps, 2008; Alexander, 2004). Shulman describes PCK as "most likely to distinguish the understanding of the content specialist from the pedagogue" (1987, p. 8). It is this complex and integrated body of knowledge, further conceptualised in the field of mathematics by Ball, Thames and Phelps (2008) which allows teachers to make informed instructional decisions about how best to present particular mathematical ideas.

A key element of this pedagogical decision-making process is actually knowing what to 1 1 ok for, Jacobs, Lamb and Philipp (2010) describe this as 'professional noticing' which o theoretrteally informed practice. Unless teachers know what to look for in terms of children's mathematical activity and understand the significance of children's particular strategies, they may rocognise certain strategies as inefficient but dismiss these as evidence of lack of prficiency or perhaps even intellectual capacity. So to consider this in an example of a single digit atditon problem (7+9): an 11 year old child might consistently achieve correct answers by setting out cubes; first by counting out seven cubes, then nine cubes and then joining both sets and gounting from 1 to arrive at 16. The child may complete many problems correctly in this . Chis /s a commonly used strategy, one which persists with children who struggle in their pathematical learning (Ostad 1997). Without observing and recognising the child's strategy ateacher might be satisfied that all the problems were correctly answered, albeit slowly. The know dge that allows a teacher to recognise the strategy and understand that it may prove to be problematic when applied to larger number $(73+96)$ is specialised, as is knowing how to interpre the child's strategy and knowing how to intervene in ways that are supportive and effieacious. Although this knowledge may be considered to be specialised it is universal in its relevance to all learners.

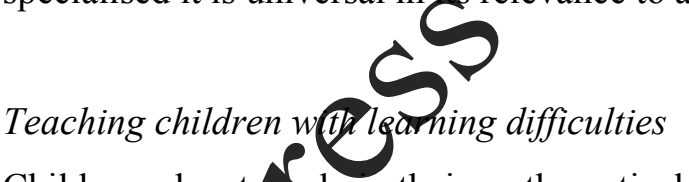

Children who straggle in their mathematical learning follow the same trajectory as those who do not struggle (Donker 2004; Geary 2004) and there is evidence of children with learning difficulties demonsfrating the same sense-making strategies as their mainstream peers (Moscardini, 2010; Behrend 2003; Empson 2003; Baroody 1996). This begs the question of what, if anything, is or might be different or unique about the knowledge base of teachers in special schools that allows them to support the mathematical learning of their pupils. Pupils_in primary special schools for children with moderate learning difficulties follow the same mathematics curriculum as their mainstream counterparts. In Scotland the content of this is outlined in Curriculum for Excellence (Scottish Government 2010) and previously in the 5-14 National Guidelines (SOED 1991); in England in the National Curriculum (DfEE 1999). These documents set out a pathway for the 


\section{Primary special school teachers' knowledge and beliefs about supporting learning in numeracy}

teaching if not the learning of the mathematics curricula and are relevant to both mainstream and special sectors.

Notwithstanding issues of definition, the group of children recognised as having moderate learning difficulties (MLD) constitutes the largest group of learners with additional support needs in the UK educational system (DCSF 2009; Norwich \& Kelly 2005; Fletcher-Campbell 2005; Crowther, Dyson, Elliot et al., 1998). Statistical evidence shows that a large percentage of this group are educated within the mainstream system (DCSF 2009). In spite of problems of definition (Norwich \& Kelly 2005; Crowther, Dyson, Elliot et al.,1998) - and it is beyond the scope of thisper to enter into discussion on the usefulness and relevance of the term moderate learning-dif sulties - it is generally accepted that this is a large and heterogeneous group of learners who gre not usually recognised until they enter the school system and whose learning difficulties are non-specific in that they experience difficulty across the curriculum. In Scotland the acategof moderate learning difficulties is no longer reported as a discrete category in Scottish Government records. There is an identified 'lack of clarity and consistency' in the collation of ata around pupils with additional support needs (HMIE, 2010, p.9). Nevertheless an Aralysis of Scottish Government Statistical Bulletins, Pupils in Scotland records from 2004 to 201 shows the learning disability group, however that might be comprised, as the largest group fopupils with additional support needs. The schools that participated in the study were classed as MLD schools, children within the schools reflected this profile of learner and mathematics as bu one of the areas of the curriculum which they had difficulty accessing.

\section{Cognitively Guided Instrugtion}

Cognitively Guided Instettiop (CGI) (Carpenter, Fennema, Franke et al., 1999) is a research-based framework which aing to help teachers understand and respond to children's mathematical thinking. CGI is built on thesis that children come to school with intuitive and informal mathematical knowledge serves as the basis for developing more formal mathematical understanding. Teachero 5 arn to focus on children's understanding; this in turn provides a context for teachers to develop their own pedagogical knowledge. Thus teacher learning becomes a dynamic process situated within classroom interactions and interpretations; by enhancing their knowledge of students' thinking teachers are better placed to design appropriate instructional tasks and to support individual student learning more effectively.

In practice CGI involves the use of mathematical word problems. In the development sessions, during the study, teachers were provided with two related research-based frameworks, one outlining the structure of word-problem types and the second relating to children's solution strategies. The first 


\section{Primary special school teachers' knowledge and beliefs about supporting learning in numeracy}

framework provides teachers with a research-based tool that can be used in practice to design instructional activities. Teachers learn that addition and subtraction can be seen as processes of joining and separating. For example in a problem such as 'There are 3 children on the bus. At the bus stop 5 more children get on. How many children are on the bus now?' the story of the problem dictates a joining action. Whereas in a problem such as 'There are 3 boys and 5 girls on the bus. How many more girls are there than boys?' there is no action in the story that suggests either joining or separating and children may come to a solution by diverse strategies which might include setting out and matching both sets and determining the difference. Understanding how word problams are structured provides teachers with a framework to inform their instruction and gande stugdents' conceptual understanding.

The second framework is research-based knowledge of children's solution strategies. This framework provides teachers with a developmental trajectory of chizdren's mathematical understanding. As pupils engage with particular problems teachers learn to interpret their intuitive solution strategies and use this analysis to inform their tachn. For example, teachers learn to recognise the difference between children using materiats to nod out problems from children using particular counting strategies or knowledge of nupber acts to solve problems. In this way, commensurate with a constructivist philosophy, tegching is a dynamic process based on building on the sense that children are making of problems by using knowledge of children's mathematical thinking to inform instruction.

\section{Research question}

This article reports findings to the specific question:

What are teachers' in pronspecial schools expressed beliefs and knowledge (pre- and postintervention) about teching and learning in numeracy for pupils with moderate learning difficulties? Study Design $y$

The study invor 12 primary teachers in three Scottish primary schools for children with moderate leatring disficulties. The schools were within the same local education authority. The maximum class syze was ten pupils. The sampling was purposeful (Patton 2002) with the involvement of three special schools permitting a replication logic, yielding findings that could be considered more robust. Replication logic involves each case undergoing individual observation and analysis prior to crosscase analysis (Yin 2003). Triangulation was supported through cross-case analyses of: initial interviews; teachers' records and accounts of pupil progress; and post-intervention, teachers' records of pupils' strategies and engagement; classroom observations by the researcher and post-intervention interviews. 


\section{Primary special school teachers' knowledge and beliefs about supporting learning in numeracy}

Given the criteria for admission into moderate learning difficulties schools, the schools and pupils within them could be considered representative of that sector within the particular local authority. Each school was invited to nominate participant teachers for the study. The study conformed to the requirements of the University of Strathclyde's Ethics Committee.

The study was designed over three phases:

\section{Phase 1}

The aim was to determine teachers' existing knowledge, beliefs and current practice prior to reing introduced to the principles of CGI. This phase involved individual semi-structured yterviews and an analysis of current planning and assessment procedures.

\section{Phase 2}

Professional development in CGI, which involved eight hours of intensivenoblem-based learning. The sessions focussed on developing an understanding of two amerks: word problem types for addition and subtraction and children's solution strategie (Capenter, Fennema, Franke et al. 1999). Teachers then ran a minimum of ten CGI setsionsin their classrooms recording their observations of children's engagement. The brevity of the professional development would be considered a limitation of the study. Time copstaints ard availability of the participants precluded more extensive professional development.

\section{Phase 3}

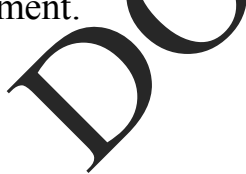

This was the post-intervention phace. The aim was to determine the effects of the professional development undertaken by the teachers in terms of changes in knowledge and beliefs and impact on practice. This phase invened the of semi-structured interviews and analysis of classroom-based observations of CGI rssions.

Analysis

Data weronalysed adhering to an iterative method, 'Framework', developed at the National Centre for Scia-Research (UK). Framework is a matrix-based analytic method that permits a rigorous and systematic analysis of data. At each stage of the analysis it is possible to work at increasing levels of abstraction with the original data being accessible at each stage of this process (Ritchie, Spencer and O'Connor 2003). All interviews were transcribed, then read and re-read. Topics were identified and grouped into categories to develop an indexing system. Once all the transcripts were indexed thematic charts were built following the framework outlined by Ritchie, Spencer and O'Connor (2003). The thematic charts allowed data to continue to be analyzed across categories by the participants and also a cross-sectional analysis of each category. To ensure reliability of the 


\section{Primary special school teachers' knowledge and beliefs about supporting learning in numeracy}

indexing, random-sampled transcripts were cross-checked by blind-coding. The final interviews were indexed using the same categories. These data were then ordered within the initial interview thematic charts permitting pre- and post-intervention analysis.

Additional hardcopy and observational data drawn from a range of sources gave an insight into classroom practices and pupil engagement. Hardcopy and observational data comprised: class planning and pupil assessment records; hardcopy and photographic evidence of pupils' work; videoclips of classroom episodes; teachers' fieldnotes; fieldnotes of researcher-observ $4 d$ CGI sessions; researcher journal comments; email correspondence.

\section{Findings}

Following the short but intensive period of professional developn ent in CGI the teachers implemented a series of ten CGI sessions in their classrooma The findings are presented comparatively, pre- and post- professional development in C 1 , and under themes that emerged through the data analysis process: subject knowledge; edaggical knowledge; knowledge of learners and beliefs about learners, learning and teaching. Pare drawn from interviews, classroom observations, fieldnotes and teachers' annotated accounts of the sessions. Pseudonyms have been applied.

\section{Knowledge}

Subject Knowledge

Prior to professional development in CGI all twelve teachers felt that their subject knowledge was sufficient for the level of teaching that they were working at with two teachers considering themselves to be 'highly kndgeable'. The general view expressed was of a knowledge level fit for the level of mathematifa instruction that might be expected of teachers working with children with learning diffieulies)

\section{'Ifeel that at mexel and also the fact that it is MLD primary... I have a good knowledge.' (Mike, Nevis Scrool) \\ thermaths we do with these children everybody is confident...' (Marjorie, Alder School)}

Although growth in subject knowledge was not anticipated following the professional development sessions the implications of knowledge growth in other areas is evidenced below.

\section{Pedagogical knowledge}

The initial interviews showed that teachers' knowledge of teaching approaches was mixed but generally limited. Two teachers acknowledged their lack of pedagogical knowledge, one teacher gave a particularly self-deprecating view, 


\section{Primary special school teachers' knowledge and beliefs about supporting learning in numeracy}

'I don't know any of it, I know absolutely nothing... you know there are different ways of teaching things, I'm sure there must be lots of different ways.' (Kirsty, Nevis School)

Several teachers talked of the importance of 'practical' approaches but these were not clearly or specifically articulated. Practical approaches generally referred to the use of concrete materials rather than to a specified pedagogical approach. This was also evidenced by the teachers' accounts of their use of resources. For example, pre-intervention Mary gave an account of practice that reflected a behavioural, transmission approach,

'...practical is, well using practical materials, cubes or whatever... and actually showing them moving the cubes exactly what they have to do.' (Mary, Lawers School)

The term 'real-life' was also used by teachers to describe desirable contexts for leaning. However this did not appear to translate into practice, as most teachers descrjbed Working with formal mathematical concepts in order that this understanding might subsequen ly be transferred into reallife situations. Although several teachers advocated real-life contefts, an analysis of lesson plans and classroom observations showed that no teacher employed realdife scengrios as a context for learning in the classroom.

Questions which probed pedagogy resulted with seren of the teachers giving an account of their knowledge of resources. One teacher expressed desire to learn more about teaching methods. Overall the teachers displayed a limited knowledg. of pedagogical approaches. The use of IT was not discussed in any detail by any eache. Specific interventions such as Maths Recovery or Numeracy Recovery were not mentioney/Although some teachers indicated the importance of counting, there were few example of discussion of children's counting. No teacher described a systematic approach to the teaching of counting.

In order to determing trov teachers were teaching for understanding and whether they were supporting childrep tome connections between their procedural and conceptual understanding, the following question was asked in the initial interview.

What do you consciously build into your practice that enables children to Nake connections between procedures and their conceptual understanding?

Nearly, very teacher found this question challenging, with some teachers unable to answer it at all even with prompting. Responses included:

'I don't know, I have never thought about that.' (Shona, Lawers School)

'I don't know if I do anything consciously, I just have a gut feeling what will work for a child.' (Helen, Nevis School)

'How do I make it meaningful? ....I really can't think.' (Mary, Lawers School) 


\section{Primary special school teachers' knowledge and beliefs about supporting learning in numeracy}

'...ehm, well I don't know if I do much of that at all ... I think it is just presumed that it is really too difficult for our children...I don't sort of think about that very much.' (Paul, Alder School)

The uncertainty conveyed by the teachers in the initial interviews contrasted notably with their responses following professional development in CGI and the application of CGI in their practice. The teachers' records, accounts and classroom observations revealed that most teachers had grasped fundamental principles relating to CGI. They were also able to adapt this learning into xisting classroom routines without the need for any organisational restructuring. Most teachers yorked with whole classes, and a few with small groups of 3 or 4 . Every teacher stated that itwas positive and beneficial experience with 10 teachers emphasising their own learning. Although the teachers quickly became familiar with problem types and found the pedagogical ramewprk CGI provided to be useful, they understood that the professional development perigd was buict and recognised that deeper learning would require more time,

Mike: ' ... when I think now about what I know about CGI, I think hat I did in the past masqueraded as problem solving because it was merely contextualised trober lifted from the workbook we were doing'

Paul :'...it was good to know exactly what kindso problems they are solving and to have a better idea of the strategies they are using to solve them'

Mary: 'This was condensed and short Ifee that I still don't know enough'

Kirsty's growth in knowledge was ngtable. From feeling that she knew 'absolutely nothing' she now stated,

'I am actually more awar what I can put into my teaching where I didn't before, I just knew I had to cover certain gurenow I can be more specific about each child'

Although working in CGI encouraged teachers to focus more on the learning than teaching, few teachers used hen observations of children's strategies to design problems specifically to extend mathematial understanding. Some teachers saw CGI as about problem-solving as opposed to a means of engaging in mathematical sense-making activity. Two teachers, Harry and Marjorie, conceptualised CGI idiosyncratically, in these cases word-problems were administered as tests of factual knowledge followed by a demonstration of what Marjorie described as 'the proper way to solve it'. Both these teachers held onto a transmission view of teaching. 


\section{Primary special school teachers' knowledge and beliefs about supporting learning in numeracy}

\section{Knowledge of learners}

This related to teachers' knowledge of individual children within their class, in general as well as specific to mathematics; it also related to their general knowledge of children's mathematical development.

Prior to professional development in CGI, every teacher had both specific and generic knowledge of their pupils, in the broadest sense they knew their pupils well. They were aware of particular areas of difficulty for particular children; they were also able to articulate an understanding of areas of difficulty that were reflective of children with moderate learning difficulty. They had good knowledge of what had been covered in the curriculum by children in their class; thi wos evidenced by assessment records. However they were less clear on children's mathematroat understanding. They were unable to specify how individual children might solve particulanmathem tical problems. All the teachers displayed only a limited knowledge of children's mathematica) development. They struggled to explain how children might solve a problem such as $\widehat{\sigma}+3$. Several teachers described how they would teach this but when probed had difficulty in explainis what children might do.

Mary: 'I would just be looking for the way they're actualy domg it. I can't even think...ehm... I don't know'. 'I really don't know what they would be doing... they say 6 and forget about the process'. (Rita,
Alder School)

Teachers did not use knowledge of childens mathematical thinking to inform planning. With the exception of one teacher whose planning was based on her own recordings and assessments of children's understanding, planning was informed by the next step set out in curriculum planners. Some teachers described planning as being informed by 'instinct', or 'gut feeling'. The need to develop knowledge in the domain of children's mathematical thinking was identified by several teachers.

No teacher demonstrated an understanding of the developmental progression in children's solution strategies inve in single digit addition and subtraction problems. Although some recognised the importar of cornting they struggled to explain how this was connected to children's solution strategies /For five teachers children's emerging strategies were seen as a deficit, for example, children's use of manipulatives was used to illustrate what they were unable to do. Two teachers' knowledge of children's mathematics was particularly confused: counting was synonymous with addition and conservation of number was confused with object permanence.

Following professional development in CGI the teachers' accounts in interview and their annotated observations showed that they were attending to children's solution strategies although they found interpreting them challenging. Teachers were beginning to identify the strategies that individual 


\section{Primary special school teachers' knowledge and beliefs about supporting learning in numeracy}

children were using with varying degrees of accuracy. This aspect of teacher learning is recognised through CGI research as requiring significant time.

Mary: 'There are things that the children are doing that (still) baffle me'

Several teachers were surprised at pupils' ability to use their own strategies and explain their solutions. Post-intervention all teachers had an increased understanding of children's mathematical thinking as well as having a language that allowed them to articulate this understanding,

Mary: 'This is probably the first programme that has given me a progression as to how to of pe them the tools to work out problems.'

Paul: 'It gives [me] an idea of what level children are operating at...I can see the ones who are still direct modelling and that shows me that their understanding of numbetisn quite as high as I perhaps thought it was.'

Importantly the teachers were focussing more deliberately gn the ctiłdren's strategies, they were more aware of what to look for. Some were redefining their role and beginning to question transmission models of teaching.

Rita: 'I am more conscious of watching them now rather than thinking about myself and how am I going to put it across to them... we were doing the ame old thing that we had done for years ...we are too busy giving them facts and I don' now enough about how they think'

Mary: 'It made me observe more closely whether they count or direct model [represent both sets in a problem usually with materials] ... it does focus your attention to detail which surprised me'

This enhanced knowledger children's understanding was also recognised as a useful framework for '...it would giverepleagues a fair idea of what ability the child had' (Anne, Nevis School)

\section{Beliefs about learners and learning}

Pre-intervention, in the initial interviews, the majority of teachers had limited or low expectations of children with learning difficulties. Learning with understanding emerged as a significant issue in these interviews with most teachers stating that learning with understanding was particularly difficult for children with learning difficulties. Only one teacher expressed a positive view of the children's potential believing that they had the ability to learn for themselves and from each other. A polarised view of learning potential emerged with some indication that the few teachers of a constructivist 


\section{Primary special school teachers' knowledge and beliefs about supporting learning in numeracy}

orientation connected the quality of learning potential to pedagogy, while those aligned to a behaviourist tradition expressed views that saw learning as a function of children's cognitive ability.

There was a frequently expressed view of children with moderate learning difficulties as unique or in some way qualitatively different from children without learning difficulties. This was evidenced by phrases such as 'our children' preceding anecdotal descriptions or unsubstantiated claims such as 'our kids... are unable to manipulate ideas' or 'I find that with MLD children, they learn best when they are moving'. This uniqueness was highlighted in terms of the relationship between procedural and conceptual understanding,

Paul: 'I think that in the MLD sector children know how to go through the routine a sum without perhaps having a real grasp of the number concepts...'.

Post-intervention every teacher felt that the pupils had benefitted. Th s was evidenced by their engagement and ability to explain their reasoning. A significan finding was that in the final interviews eleven of the twelve teachers stated that they had inderestimated children's potential, particularly in their ability to explain; one teacher maintained a trong 'within-child deficit' stance. There was surprise that children with moderate learning difficulties were using the same strategies to solve problems as children without learning difficultes

Paul: 'What it has shown me is that childrenamorking with their understanding of number... it highlights the range and ability in a different vay... can see the ones who really do need support to make those number connections'

\section{Beliefs about teaching}

Pre-intervention most teachers believed practical approaches were of value for pupils with moderate learning difficulties. In liferith the teachers' knowledge of pedagogy presented above, these 'practical' approachesaffrogh considered important, were generally undefined. 'Practical' in terms of teachers' expressedpedagogies rested more on the use of materials rather than on any contextual settings or reafle scenarios. 'Variety' was a word frequently used to describe what was believed important in teabing children with moderate learning difficulties. However when unpackaged this ustally fefred to a diversity of resources rather than to a range of pedagogical approaches.

Nine of the twelve teachers believed that effective teaching of children with moderate learning difficulties required a transmission approach through explicit strategy instruction. One teacher, advocated discovery approaches. Although several teachers believed it was important to encourage children to make connections in their mathematical thinking and to be able to transfer and apply this knowledge in real-life situations this was not reflected in their practice. 


\section{Primary special school teachers' knowledge and beliefs about supporting learning in numeracy}

Following the intervention teachers were beginning to question their previously held views about transmission approaches and were beginning to talk in terms of mediated learning, although one teacher held onto a transmission view.

'It has made me realise that we tend to meddle too much in children's learning... we want to do it for them but now you can stand back and let them get on with it and only really step in if they have a major problem ... you still mediate, you still encourage them' (Lianne, Lawers school)

Helen: '... it has opened my mind to the way children think. There is too much pressyerput ony
children ... this way you are actually encouraging children to play with numbers gnd youre creating an environment for them.'

Procedural competency was considered important by many of the teacher. For gne teacher it was sufficient in itself. He viewed the ability to compute without conceptual undentanding as a satisfactory outcome. Five teachers viewed it as a pre-requisite to be to attend to problems. An analysis across categories revealed that the teachers who placed the most importance on procedural skills were those whose pedagogy and didactics followed trasm ssion approach.

Following the development of CGI in their classroons most teachers were beginning to reveal the importance that they were now placing on chiłtren's mathematical thinking; the notion of children making 'connections' permeated the final interview. This was a marked shift away from previously expressed views of procedural compency sufficient. The impact that this was having on their teaching was apparent in terms of the impylance that the teachers were now giving to accessing this thinking, some teachers were recognsing that previously this had not been the case.

Kirsty: 'I am starting to kn lot more, a lot more than I had before ... as I said before, I didn't really understand a lo hat was going on... I actually lost the kids and I couldn't see what they were doing.'

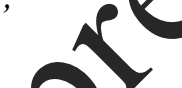

Rita: 'It has beengood for me, it has given me more understanding of watching how their minds if thatmakes sense.

\section{Discussion}

The findings are consistent with previous American studies (Carpenter et al, 1999; Carpenter et al. 1988) in finding that prior to professional development teachers were operating at an intuitive level with fragmented knowledge of children's mathematical thinking. Pre-intervention there was no evidence of the type of specialised pedagogical knowledge unique to mathematics teaching called for by Ball, Thames and Phelps (2008), which allows teachers to look for and understand student errors 


\section{Primary special school teachers' knowledge and beliefs about supporting learning in numeracy}

and misconceptions and which in turn informs teaching. It also reflects concerns with mathematics education in the UK arising due to a 'lack of pedagogy' (Ryan \& Williams, 2007, p.5), a systemic failure to connect theory and practice and a misplaced focus on improving teachers rather than teaching (Hiebert \& Morris, 2012; Hiebert, Gallimore \& Stigler, 2002). The challenge of learning with understanding for children with learning difficulties should be seen not as a within-child deficit, but as a problem of pedagogy and the requisite pedagogical knowledge (Ball, Thames \& Phelps, 2008; Florian, 2008; Anthony \& Walshaw, 2007).

Although the current investigation was a small-scale study and the results cannot be gemeralisede, the findings showed that, prior to professional development, the participating teachers did not demonstrate a depth of knowledge about children's mathematics that would position hem to support children's mathematical learning effectively. Post-intervention however the pgsitive message from the study was that the participants were highly receptive to the professionalevelopment and they recognised the value of this to their practice. It should be noted that the study related to a particular area of mathematics teaching with children with learning difficulties. No claims are being made about the generalisability of the findings to other areat mathematics or to other domains of learning. Consideration might also be given to the exrent to which it may be useful for teachers to develop a deeper understanding of psychologieal aspects of learning, particularly for pupils with more significant difficulties in learning.

The findings show that pre-intervention, in 2 rms of 'professional noticing' (Jacobs, Lamb \& Philipp, 2010) which is that capacity to recegnise, understand and respond to children's conceptualisations, the participating teachers did not know what to look for. They knew the curriculum programme and they could identify nexteps $n$ this basis but they lacked knowledge of children's developmental trajectory in mathemarics. Host participants believed that their subject knowledge was sufficient but they were generaty unaware of the body of research-based knowledge of children's mathematics that could be pe hed in their classrooms. This is not to apportion blame on the teachers. There are issues of rofessional development at every level, from initial teacher education to post-qualifying that requre to be considered (Ryan \& Williams, 2007). In the absence of this research-based knowledge about learning, teachers were reliant on the intuitive beliefs described by Turner, Christensen and Meyer as stemming from 'common sense' and experiences in education (2009, p.361)

The lack of detailed knowledge of what children do in mathematics was evidenced by the particular difficulty teachers had in explaining what children might do when adding $6+3$, along with their struggle to account for their pedagogy in terms of supporting conceptual understanding. Such 


\section{Primary special school teachers' knowledge and beliefs about supporting learning in numeracy}

knowledge may be deemed to be 'deep' knowledge and an indicator of quality of practice in schools, at least as far as guidance disseminated to Scottish schools is concerned (HMIE 2011), but without a clear account in specific domains of what characterises 'deep' knowledge the term is little more than rhetoric that fails to inform and support teachers and consequently pupils. Yet there is a body of research that indicates what this deep knowledge entails in terms of children's mathematical thinking (Baroody \& Dowker 2003; Carpenter et al. 1999; Fuson 1988; Steffe et al. 1983) and how such knowledge might inform practice (Carpenter Franke \& Levi 2003; Fosnot \& Dolk 2001; Anghileri 2000). The challenge is not in delineating this knowledge base, it is in developing its usein practice through professional development activity that is both effective and sustainable.

It is interesting to note that all of the teachers believed their subject knowledge was sufficient for teaching children with learning difficulties but following professional delopment they recognised that the required knowledge was more complex. This specialised knawledgeidomain specific (Ball Thames \& Phelps, 2008) rather than sector specific. Further resefrch would be required to determine the extent of the existence, or absence, of this knowledge base wrth the special sector. It brings into question the belief that specialized knowledge resides an setor rather than recognising this as about individual teachers having developed a deep and integrated body of knowledge in particular domains, in this case numeracy. A deep/anderstanding of how children conceptualise and misconceptualise mathematical principles al bws tyachers to make instructional decisions that are supportive and responsive to the paricular understandings of the individual. This supports the concept of inclusive pedagogy in recognising the capacity that children have to make sense of their learning, in other words the 'transf mability' described by Hart, Drummond and McIntyre (2007). In this respect the growth in knowledge demonstrated by the teachers reflected a change in beliefs (Lloyd, 2002) about the rearnes, and in particular about their capability. Prior to developing CGI in their classrooms thegethers displayed commonly held views of within-child deficits with no indication of the thed to question pedagogy (Lalvani, 2013).

The special education system has been described as a mechanism for the identification and removal from nainstream schools of children whose needs might be best met elsewhere (Dyson 2001; Barton 1997; Tomlinson 1982) with an expectation of support that is in some way qualitatively different from that available in a mainstream setting (Florian, 2008). This separatist function sits uneasily with the counter-proposition that there is no distinct pedagogy required that is unique to children with moderate learning difficulties (Fletcher-Campbell, 2005; Lewis \& Norwich, 2005). The tension generated by this anomaly is a real one, neatly expressed by Thomas and Loxley, (2007) who state that 'children who are difficult to teach have become by default 'special' children and teachers have begun to believe that they are not skilled enough to deal with 'special' children' (p.27). An extension 


\section{Primary special school teachers' knowledge and beliefs about supporting learning in numeracy}

of this logic is that if some teachers in mainstream schools feel ill-equipped to support the learning of some children in core curricular areas then it would be reasonable to assume that these children would benefit from the expertise of teachers in the special sector and that such expertise resides there. This is in line with the argument that the justification of a category rests on the educational benefits gained from any additional or different provision that results from that categorisation (Norwich \& Kelly 2005, p.36). On this basis an expectation of educational benefit through effective support in core curricular areas such as literacy and numeracy would not seem unreasonable. The unique expertise believed to reside in the special sector is frequently used as a justification for the continued existence of segregated provision. Arguably the issue is that the absence of such knowledge constrains inclusive practice regardless of the setting.

\section{Conclusion}

The development of a knowledge base that permits an inclusivg pedagogy is of relevance to all teachers and should not be seen as sector specific, teachers need to beand feel equipped to support all learners. It involves having depth of knowledge and understanding in specific domains and refraining from seeing expertise as residing elsewhere. It fecognises the importance of learning and development from the point of view of the teacher as as the child; learning and teaching is seen as a dynamic process situated in teacher-p pil meractions. Such interactions afford teachers an insight into children's conceptualisations that dan then inform teaching purposefully. The relevance of a knowledge base which supports thin kin of practice and the effect this may have on teachers' beliefs was clearly expressed in the final inkerview by one teacher,

'It has been quite an eye-opener for me I must admit....I can teach them and they can learn it but they might not understand Lnever gave that a second thought before. Quite honestly if they could do it I was happy, I'm nt?

\section{References}

Alexander, R. (204). Still no pedagogy? Principle, pragmatism and compliance in primary

Education. Cambridge Journal of Education, 34, no.1, 7-33.

Anghileny. (2000). Teaching number sense. London: Continuum.

Anthony, G. \& Walshaw,M. (2007). Effective pedagogy in mathematics/Pangarau:Best evidence synthesis iteration [BES]. Wellington: Learning Media.

Askew, M., M. Brown, V. Rhodes, D. Johnson, \& D. Wiliam. (1997). Effective teachers of numeracy - Final report: report of a study carried out for the Teacher Training Agency1995-1996 bythe School of Education, King's College London. London: King's College.

Ball, D. L., Thames, M. H. \& Phelps,G.. (2008). Content knowledge for teaching. What makes it special? Journal of Teacher Education, 59, no.5, 389-407. 


\section{Primary special school teachers' knowledge and beliefs about supporting learning in numeracy}

Baroody, A.J. (1996). Self-invented addition strategies by children with mental retardation. American Journal on Mental Retardation, 101, 72-89.

Baroody, A. J. \& A. Dowker.eds. (2003). The development of arithmetic concepts and skills: Constructing adaptive expertise. Mahwah, NJ: Lawrence Erlbaum Associates.

Barton, L. (1997. The politics of special educational needs. In L. Barton \& M. Oliver (Eds.) Disability studies: Past present and future. Leeds: The Disability Press .

Behrend, J.L. (2003). Learning-disabled students make sense of mathematics. Teaching Children Mathematics, 9,5, 269-274.

Carpenter, T.P., M.L. Franke, \& L. Levi. (2003). Thinking mathematically-integrating arithmetic and algebra in elementary school. Portsmouth, $\mathrm{NH}:$ Heinemann.

Carpenter, T.P, E. Fennema, M. L Franke, L. Levi \& S.B. Empson. (1999). Children's mathematics: Cognitively guided instruction. Portsmouth, NH: Heinemann

Carpenter, T.P., E. Fennema, P.L. Peterson, \& D.A. Carey. (1988). Teachers'pedagogica content knowledge of students' problem solving in elementary arithmetic. Jou rnal for Research in Mathematics Education, 19, no.5, 385-401.

Crowther, D.,A. Dyson, J. Elliot, \& A. Millward. (1998). Costs and out omes for pupils with moderate learning difficulties (MLD) in special and manstream schools, Research Report RR89. London: DfEE.

DCSF ( Department for Children Schools and Families) (2009). Children with special educational needs 2009: an analysis. Nottingham: BCSF.)

DCSF (2008). Independent review of mathematics teaching nearly years settings and primary schools-final report. Nottingham:DGSF.

DfEE (Department for Education and Employment) (1999). The national curriculum London: HMSO.

Donaldson, G. (2011). Teaching Scotland trute-keport of a review of teacher education in Scotland. Edinburgh: Scottish Gover ment.

Dowker, A. (2004). What works for children with mathematical difficulties? Research Report RR554. University of Oxfordy DfES.

Dyson, A. (2001). Special needs education as the way to equity: an alternative approach? Support for Learning, 16, no.3, $99-104$.

Empson, S.B. \& D. Junk 2004). Teachers' knowledge of children's mathematics after implementing student-centred curriculum. Journal of Mathematics Teacher Education, 7, 121-144.

Empson, S. B. 2003 . Low-performing students and teaching fractions for understanding: An interâtional analysis. Journal for Research in Mathematics Education. 34, (4), 305-343.

Fennema,E., Fra)ke,M.L., Carpenter,T.C. \& Carey,D.A.. (1993). Using children's knowledge in nstruction. American Educational Research Journal, 30, no.3, 555-583.

FletcherCampbell, F. (2005). Moderate learning difficulties. In A. Lewis \& B. Norwich eds. Special teaching for special children? Pedagogies for inclusion Berkshire: Open University Press.

Florian, L. (2008). Special or inclusive education: future trends. British Journal of Special Education, 35, no.4, 202-8.

Florian, L. \& Black-Hawkins, K. (2011). Exploring inclusive pedagogy, British Educational Research Journal, 37, 5, 813-828, [Online] DOI: 10.1080/01411926.2010.501096

Florian, L. \& Linklater, H. (2010). Preparing teachers for inclusive education: Using inclusive pedagogy to enhance teaching and learning for all. Cambridge Journal of Education, 40(4), 369-386. doi:10.1080/0305764X.2010.526588 


\section{Primary special school teachers' knowledge and beliefs about supporting learning in numeracy}

Fosnot, T. C. \& Dolk,M. (2001). Young mathematicians at work- constructing number sense, addition and subtraction. Portsmouth, $\mathrm{NH}:$ Heinemann.

Fuson, K.C. (1988). Children's counting and concepts of number. New York : Springer- Verlag.

Geary, D.C. (2004). Mathematics and learning disabilities. Journal of Learning Disabilities, 37 , no.1, 4-15.

Greer, D.L. \& Meyen,E.L. (2009). Special education teacher education: A perspective on content knowledge, Learning Disabilities Research and Practice, 24, (4), 196-203.

Hart,S., Drummond, M.J. \& McIntyre, D. (2007). Learning without limits: Constructing a pedagogy free from determinist beliefs about ability. In L. Florian (Eds) The SAGE handbook of special education. London: Sage.

Hiebert, J. \& Morris,A.K. (2012). Teaching rather than teachers as a path toward improving classroom instruction. Journal of Teacher Education, 63, No.2, 92-102.

Hiebert, J., Gallimore, R. \& Stigler, J.W. (2002). A knowledge base for the teacten profession: what would it look like and how can we get one? Educational Researcher, 31, no.5, 3-15.

Her Majesty's Inspectorate of Education (HMIE) (2011). The journey to excellence. Available at http://www.journeytoexcellence.org.uk/Images/LT\%20IC\$\%20Meeling\%20Children $\% 27 s \% 20 N e e d s$ tcm 4-604897.pdf

HMIE (2010). Review of the Additional Support for Learning Ad Ading benefits for learners. A report by HMIE to Scottish ministers, November 20 (0. Avgilable at http://www.hmie.gov.uk/documents/publication/ravaaul.pdf

Jacobs, V. R., Lamb, L.L.C., \& Philipp, R.A.. (2010). Professional noticing of children's mathematical thinking, Journal for Researcy in Mathematics Education, 41, no.2, 169-202.

Lalvani, P. (2013). Privilege, compromiserorseciaz justice: teachers' conceptualizations of inclusive education. Disability \& Socity, 28, no. 1, 14-27, $\mathrm{http}: / / \mathrm{dx}$.doi.org/10.1080/09687599.2012.692028

Lewis, A \& B. Norwich (eds.) (2005). Speeial teaching for special children? Pedagogies for inclusion. Berkshire: Open University Press.

Lloyd, G. (2002). Mathematics teachers' beliefs and experiences with innovative curriculum materials. In G.C $\mathrm{Leg}$, E. Pehkonen \& G.Törner eds. Beliefs: A hidden variable in mathematics. DGerry ct, Netherlands: Kluwer Academic Publishers.

Ma, L. (1999). Kngr ring ynd teaching elementary mathematics : teachers' understanding of fundame mathematics in China and the United States. Mahwah, N.J.: Lawrence Erlbarm ssociates.

Maclellan, E. (2012). Number Sense: The Underpinning Understanding for Early _; Quantitative Literacy, Numeracy: 5: Iss. 2, Article 3. DOI:

hep://dx.doi.org/10.5038/1936-4660.5.2.3

Middlo.6n, K. (Executive Producer) (2010). Dispatches: Kids don't count. Available at http://www.channel4.com/programmes/dispatches/episode-guide/series-53/episode-1

Moscardini, L. (2010). 'I like it instead of maths': How pupils with moderate learning difficulties in Scottish primary special schools intuitively solved mathematical word problems. British Journal of Special Educational Needs, 37, (3), 130-138.

Norwich, B. \& Kelly,N. (2005). Moderate learning difficulties and the future of inclusion. London: Routledge-Falmer.

Norwich, B. \& Nash. T. (2011). Preparing teachers to teach children with special 


\section{Primary special school teachers' knowledge and beliefs about supporting learning in numeracy}

educational needs and disabilities: the significance of a national PGCE development and evaluation project for inclusive teacher education, Journal of Research in Special Educational Needs, 11 no. 1, 2-11.

Ostad, S.A. (1997). Developmental differences in addition strategies: comparisons of mathematically disabled and mathematically normal children. Journal of Educational Psychology, 67, 345-357.

Patton, M.Q. (2002). Qualitative research and evaluation methods. Thousand Oaks, Ca: Sage.

Peterson, P.L., Fennema, E., Carpenter T. \& Loef, M. (1989). Teachers' pedagogical content beliefs in mathematics. Cognition and Instruction, 6, no.1, 1-40.

Ritchie, J., Spencer, L. \& O'Connor, W. (2003). Carrying out qualitative analysis. In J.Ritchie \& J.Lewis eds. Qualitative research practice- A guide for social science researchers. London: Sage.

Ryan, J. \& Williams, J. (2007). Children's mathematics 4-15 -Learning from errors ank misconceptions. Berkshire: Open University Press.

Scottish Office Education Department (SOED). (1991). Curriculum and assessment in Scotland, National Guidelines: Mathematics 5-14. Edinburgh: Scottish Off ce Education Department.

Scottish Government (2010). Curriculum for excellence-Mathematigs experes and outcomes. Available at http://www.ltscotland.org.uk/myexperiencesandoutcomes/manematics/index.asp

Shulman, L.S. (1986). Those who understand: Knowledge gowth $\mathrm{n}$ teaching, Educational Researcher, 15, no.2, 4-14.

Steffe, L. P.,E. von Glaserfeld, J.Richards \& P.Cobb. Children's counting types: Philosophy, theory, and application. Nemyork: Praeger.

Thomas, G. \& A. Loxley. (2007). Deconstructing special education and constructing inclusion $2^{\text {nd }}$ Edition. Berkshire: Open Universty Pross.

Tomlinson, S. (1982). A sociology of special education. London: Routledge \& Kegan Paul.

Turner, J.C., Christensen, A. \& Meyer, DK. 2009). Teachers' beliefs about student learning and motivation. In L.J. Saha, A.G.Dworkin (eds.), International handbook of research on teachers and teaching. New ork: Springer.

Walshaw, M. (2012). Teacher knowledge as fundamental to effective teaching practice Journal of Mathem Teacher Education 15, no.3, 181-185. DOI 10.1007/s10857-0129217-0

Wilson, M. \& Coopd T (2003). Mathematics teacher change and development. In G.C. Led, E. Pehkonen \& G.Törner (Eds.) Beliefs: A hidden variable in mathematics educa top? Dordrect, Netherlands: Kluwer Academic Publishers.

Yin, RNR. 2003). Case study research-Design and methods (3rd edition). Thousand Oaks: Sage.

Yloner, A. \& Norwich, B. (2012). Using lesson study to develop teaching approaches for secondary pupils with moderate learning difficulties: teachers' concepts, attitudes and pedagogic strategies. European Journal of Special Education, 1-17, iFirst Article. 